\title{
Perceval S and Coronary Artery Bypass Grafting, Contradiction or Full Harmony?
}

\author{
Sara Badia*, Elisabet Berastegui, M Luisa Cámara, Luis Delgado, Claudio Fernández, Ignasi Julià, Bernat Romero, \\ Anna Llorens, Paula Albaladejo and Xavier Ruyra \\ Cardiac Surgery Department, Hospital Universitari Germans \\ *Corresponding author \\ Trias i Pujol, Badalona, Barcelona, Spain. \\ Sara Badia, Cardiac Surgery Department, Hospital Universitari \\ Germans Trias i Pujol, Badalona, Barcelona, Spain, E-mail: sara. \\ badia@hotmail.com.
}

Submitted: 02 Dec 2016; Accepted: 13 Dec 2016; Published: 17 Dec 2016

\begin{abstract}
Background/Study Objective: Coronary artery disease is very common in patients who are referred to aortic valve replacement. Concomitant coronary artery bypass grafting (CABG) procedure does not necessarily contradict with the use of last generation sutureless bioprostheses, but, publications about this combined approach are very limited. The objective of this study is to describe the results of aortic valve replacement plus CABG using Perceval $S$ aortic sutureless bioprostheses in our Center.
\end{abstract}

Methods: From our database we retrospectively described the outcomes of 42 patients who underwent aortic valve replacement with a last generation sutureless bioprostheses (Perceval S) plus CABG at the same procedure. We used a combination of arterials (left internal mammary artery (LIMA), right internal mammary artery (RIMA) and radial artery) and saphenous vein for the coronary artery bypass grafting. Most of the patients received 1 bypass (range: 1-3). Mean age: 78,19 \pm 5,1. Male 64,3\%, female 35,7\%. Cardiovascular risk factors: Hypertension 97,6\%; Diabetes 38,1\%, Dyslipidemia 69\%, peripheral vascular disease 38,2\%, prior stroke 9,5\%, chronic renal failure 40,5\%, obstructive pulmonary disease $21,4 \%$ of the patients. Mean Logistic EuroScoreI/II: 16,68/10,73\% (expected mortality).

Results and Conclusions: Excellent results were achieved in patients undergoing aortic valve replacement with Perceval S sutureless bioprostheses and concomitant coronary artery bypass grafting. Although high aortotomy is needed for Perceval S implantation, is possible to perform proximal anastomosis for saphenous grafts properly. Perceval $S$ is a feasible alternative for patients with aortic valve stenosis and coronary artery disease, with shorter cross-clamp and extracorporeal circulation times and low rate of complications.

Keywords: Aortic valve replacement, Coronary artery bypass grafting, Sutureless valve.

\section{Introduction}

Over the past 10-15 years, there has been a significant change in the cardiac surgery environment manifested by a decline in the volume of $\mathrm{CABG}$ surgeries being performed. The shift in revascularization practices from surgery to $\mathrm{PCI}$ has resulted in a reduction in the overall number of CABG surgeries. And growing for aortic valve replacement.Isolated aortic valve replacement represents a $44,1 \%$ of the total cardiac surgeries in our Country been the predominant cardiac surgical pathology, representing the "body" of the activity in each Department [1].

Traditionally, aortic valve surgery has generally been performed via full sternotomy incision with the use of biological or mechanical stented valves sutured to the aortic annulus. However, the increase in number of older patients and patients with multiple comorbidities has prompted the need for developing techniques that are less invasive in order to improve postoperative recovery by reducing the extracorporeal circulation and crossclamp times, reducing the complications derived therefrom. In actual fact the emergence of possible transcatheter aortic-valve implantation (TAVI) option for management of aortic valve disease has demanded the development of alternative and more attractive surgical options.

Perceval $\mathrm{S}$ bioprostheses is a last generation suture-less aortic prostheses. These new prosthesessave X-clamp and EEC time, and favor the implantation in small aortic root, the easy implantation along with the time saving of extracorporeal circulation, makes this prostheses a good alternative for high risk patients who need an aortic valve replacement.

Combined surgery of coronary artery bypass grafting plus aortic valve replacement is a very usual procedure. The use of this 
last generation valve is not a contradiction with a myocardial revascularization procedure. We described the experience of this combined surgery in our Center.

\section{Materials and Methods}

A descriptive and retrospective study was created collecting a total of 42 patients from our database. We review the clinical and procedural outcome data from the $100 \%$ of the patients. The inclusion criteria were: patients which had undergone aortic valve surgery using Perceval S bioprostheses with concomitant coronary artery bypass grafting. Transesophageal echocardiography (TEE) was done in every case and an experienced echocardiographer was present to interpret findings in the operating room and also, before discharge.

The preferent pathology treated was pure aortic valve stenosis with a rate of $77,8 \%$, mixed stenos is-regurgitation disease was present in $22,2 \%$. The demographic data of the 42 patients analyzed are collected in the table 1 . The mean age reach 80 years old, sample is composed by older and high risk patients (16, 68\% euro Score I).

\begin{tabular}{|l|c|}
\hline & $\mathbf{n}=\mathbf{4 2}$ \\
\hline Mean age (yearsold) & $78,19 \pm 5,1$ \\
\hline Gender: men/women & $64.3 \% / 35.7 \%$ \\
\hline Hypertension & $97.6 \%$ \\
\hline Diabetes & $38.1 \%$ \\
\hline Chronic Obstructive Pulmonary Disease (COPD) & $21.4 \%$ \\
\hline Dyslipidemia & $69 \%$ \\
\hline Peripheral vascular disease & $38,2 \%$ \\
\hline Prior stroke & $9,5 \%$ \\
\hline Chronic renal failure & $40,5 \%$ \\
\hline Mean logisticEuroScore II & $10.73 \%$ \\
\hline
\end{tabular}

Table 1: Demographic data.

How to implant the sutureless valve in a combined surgery Canulation is performed as usual. Keep in mind left a proper space for proximal anastomosis and aortotomy. Before start the cannulation is necessary to plan where to place the cannulas for having space enough for the proximal anastomosis of the bypass (if needed). This simple trick is the only thing that you must take into account for make possible this combined procedure, because for implanting a Perceval S you need to establish extracorporeal circulation and make the aortotomy higher than usual $(2 \mathrm{~cm}$ above the sinotubular junction).

After the aortic valve exposition a complete excision and removal of the aortic leaflets and debridement of the calcium of the annulus is required as standard fashion. Next step is the measurement of aortic annulus for choosing the prosthesis size. After that we place 3 temporary guide sutures in the lower point of the sinuses (nadir). Guide sutures are inserted through the prosthesis buttonholes. Fit the prostheses within the annulus and valve deployment. Ballooning of the valve stent during 30 seconds at 4 atmosphere of pressure with the infusion of warm saline. Aortotomy is closed.
After that, proximal anastomosis are performed if necessarily.

Regarding the statistical analysis, the variables are presented as mean, median, range and percentage. For the statistical treatment was used the Statistical Package for Social Sciences (SPSS) software version 20 .

\section{Results}

The surgical outcomes are described in table 2 . The mean crossclamp time was 69 minutes with a mean extracorporeal circulation time of 96 minutes. The majority of the patients needed 1 bypass, with a predominance of the use of left internal mammary artery following by saphenous vein. The mean Length Hospital Stay (L.O.S) in the intensive Care Unit (ICU) was 7 days but the median was 2,5 days. The global LOS was 19 days of mean with a median of 10 days.

\begin{tabular}{|l|l|}
\hline & $\mathbf{n}=\mathbf{4 2}$ \\
\hline -Crossclamp times (minutes) & $-69,26 \pm 23,2$ \\
-Bypass time (minutes) & $-96,60 \pm 30,1$ \\
\hline L.O.S Intensive Care Unit. Mean (range) & $-7,14$ days $(1-56)$ \\
Global L.O.S Hospital. Mean (range) & $-18,83$ days $(8-76)$ \\
\hline Number of Bypass & \\
1/ & $59,5 \%$ (25patient) \\
2/ & $21,4 \%$ (9patients) \\
3/ & $19 \%$ (8patients) \\
\hline Graft: & \\
LIMA & $-71,4 \%$ (30patients) \\
RIMA & $-2,4 \%$ (1patient) \\
Radial artery & $-4,8 \%$ (2patients) \\
Saphenousvein & $-50 \%$ (21patients) \\
\hline
\end{tabular}

Table 2: Surgical Outcomes

The complications are described in the table 3. Only one patient suffered a neurological complication, been transient stroke with recovery ad integrum. Only 2 patients needed reoperation for bleeding during the first $24 \mathrm{~h}$ post-surgery. For the evaluation of preoperative surgical risk we used the logistic euroSCORE I and euroSCORE II. The expected mortality compared with observed is described in table 3 and represented in figure 1. Analyzing mortality, observed was lower than expected by euroSCORE I and also lower than the estimated by euroSCORE II.

\begin{tabular}{|l|c|}
\hline & $\mathbf{n = 4 2}$ \\
\hline Transient Stroke (\%) & $2,4 \%$ (1 patient) \\
\hline Reoperation for bleeding & $4,8 \%$ (2 patients) \\
\hline Endocarditis & none \\
\hline Mediastinitis & none \\
\hline Multiple organ failure & $2,4 \%$ (1patient) \\
\hline Estimated risk & $16,68 \% \pm 4,1$ \\
EuroScore I & $10,73 \% \pm 3,6$ \\
EuroScore II & $7,1 \%$ (3 patients) \\
\hline Mortality (\%) &
\end{tabular}

Table 3: Complications. 


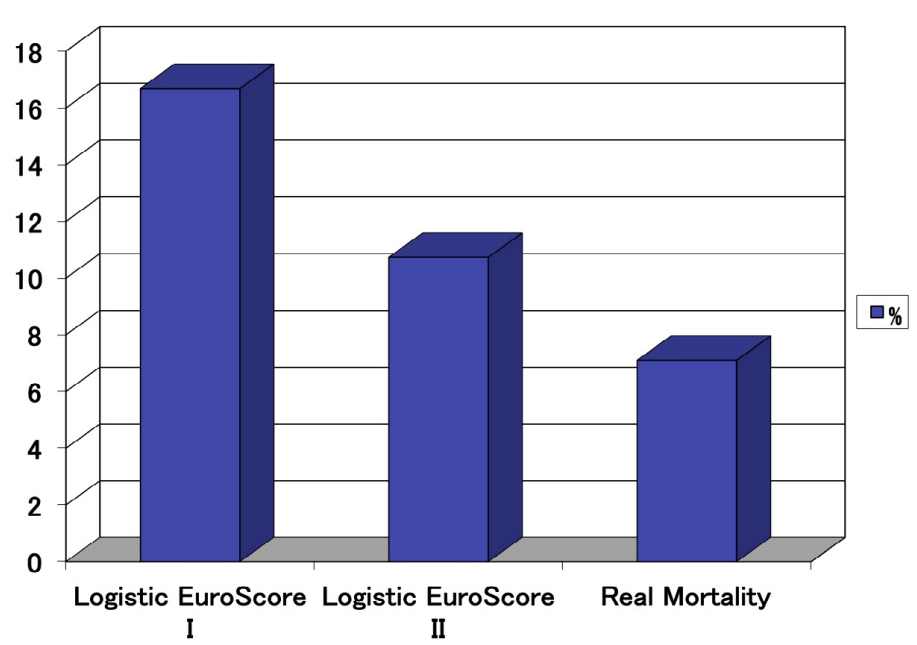

Figure 1: Expected mortality compared with observed.

\section{Conclusions}

Several authors described their results with the use of Perceval $\mathrm{S}$ bioprostheses in high risk patients, with minimally invasive approach or in combined surgery [2-10]. However no one describes the experience of combined Perceval $\mathrm{S}$ aortic valve replacement with concomitant myocardial revascularization. Perceval Saortic valve replacement (AVR) in a combined surgery with coronary artery bypass grafting $(\mathrm{CABG})$ can be done with excellent results in terms of mortality and morbidity.

For combined Perceval AVR $+\mathrm{CABG}$, is necessary to plan where to place the proximal venous anastomosis before the cannulation. Perceval S is an easy, safe and feasible alternative for high risk patients with aortic valve stenosis and coronary artery disease.

\section{Advantages}

Shorter cross-clamp and extracorporeal circulation times and lower rate of complications also in high risk and older population.

\section{Acknowledgement}

The authors wish to thank to each member of the departments involved who has made this possible.

\section{References}

1. Bustamante-Munguira J, Centella T, Polo L, Hornero F (2015) Cirugía cardiovascular en España en el año 2014. Registro de intervenciones de la Sociedad Española de Cirugía TorácicaCardiovascular (SECTCV). Cir Cardiov 22: 297-313.

2. Forcillo J, Bouchard D, Nguyen A, Perrault L, Cartier R, et al. (2016) Perioperative outcomes with sutureless versus stented biological aortic valves in elderly persons. J Thorac Cardiovasc Surg 151: 1629-1636.

3. Takagi H, Umemoto T (2016) A Meta-Analysis of Sutureless or Rapid-Deployment Aortic Valve Replacement.Thorac Cardiovasc Surg 64: 400-409.

4. Laborde F, Fischlein T, Hakim-Meibodi K, Misfeld M, Carrel T, et al. (2016) Cavalier Trial Investigators. Clinical and haemodynamic outcomes in 658 patients receiving the Perceval sutureless aortic valve: early results from a prospective European multicentre study (the Cavalier Trial). Eur J Cardiothorac Surg 49: 978-986.

5. Lio A, Scafuri A, Nicolò F, Chiariello L (2016) Valve Replacement with a Sutureless Aortic Prosthesis in a Patient with Concomitant Mitral Valve Disease and Severe Aortic Root Calcification. Tex Heart Inst J 43: 186-188.

6. Nguyen A, Fortin W, Mazine A, Bouchard D, Carrier M, et al. (2015) Sutureless aortic valve replacement in patients who have bicuspid aortic valve. J Thorac Cardiovasc Surg 150: 851-857.

7. Miceli A, Gilmanov D, Murzi M, Marchi F, Ferrarini M, et al. (2016) Minimally invasive aortic valve replacement with a sutureless valve through a right anterior mini-thoracotomy versus transcatheter aortic valve implantation in high-risk patients. Eur J Cardiothorac Surg 49: 960-965.

8. Beckmann E, Martens A, Alhadi F, Hoeffler K, Umminger J, et al. (2016) Aortic valve replacement with sutureless prosthesis: better than root enlargement to avoid patient-prosthesis mismatch? Interact CardiovascThorac Surg 22: 744-749.

9. Chandola R, Teoh K, Elhenawy A, Christakis G (2015) Perceval Sutureless Valve - are Sutureless Valves Here? Curr Cardiol Rev 11: 220-228.

10. Shrestha M, Folliguet TA, Pfeiffer S, Meuris B, Carrel T, et al. (2014) Aortic valve replacement and concomitant procedures with the Perceval valve: results of European trials. Ann Thorac Surg 98: 1294-1300.
Copyright: @2016 Badia S, et al. This is an open-access article distributed under the terms of the Creative Commons Attribution License, which permits unrestricted use, distribution, and reproduction in any medium, provided the original author and source are credited. 